Article

\title{
Learning Experiences of Students Who Are Hard of Hearing in Higher Education: Case Study of a South African University
}

\author{
Diane Bell ${ }^{1, *}$ and Estelle Swart ${ }^{2}$ \\ ${ }^{1}$ Business School, Stellenbosch University, 7602 Stellenbosch, South Africa; E-Mail: diane.bell@usb-ed.com \\ 2 Educational Psychology, Stellenbosch University, 7602 Stellenbosch, South Africa; E-Mail: estelle@sun.ac.za \\ * Corresponding author
}

Submitted: 25 June 2018 | Accepted: 27 July 2018 | Published: 6 December 2018

\begin{abstract}
Students who are hard of hearing $(\mathrm{HOH})$ are being granted access to university increasingly, yet they remain significantly under-represented and under-supported, often resulting in poor academic outcomes with elevated levels of attrition. This situation places a growing obligation on universities to improve the support provided to these students in order to have a positive influence on their overall academic experience and eventual economic independence. This trend is relevant to South Africa, where Higher Education Institutions (HEIs) are accepting and registering students with a hearing loss but are not providing adequate academic support and inclusive curricula. Furthermore, in South Africa, almost no research has been conducted concerning students who are $\mathrm{HOH}$ in higher education regarding their teaching and learning needs or the coping strategies which they use to survive academically. However, what is known is that, of those $\mathrm{HOH}$ students who do enter higher education, many do not graduate successfully (up to 75\%) and, of those that do graduate, many continue to be excluded from professions. The aims of this article were to report on the teaching and learning experiences of students who are $\mathrm{HOH}$ at a South African university, who prefer to make use of spoken language, to share the daily barriers with which they are faced, and to provide recommendations for teaching and learning, as well as curricula transformation. This study adds to the existing body of knowledge on this topic in South Africa and could be relevant in similar contexts.
\end{abstract}

\section{Keywords}

deaf; disability; hard of hearing; higher education; inclusive curricula; hearing impairment; South Africa; teaching; university

\section{Issue}

This article is part of the issue "Students with Disabilities in Higher Education", edited by Geert Van Hove (Ghent University, Belgium/VU Amsterdam, The Netherlands), Minne Bakker (VU Amsterdam, The Netherlands) and Alice Schippers (Disability Studies in the Netherlands/VU Amsterdam, The Netherlands).

(C) 2018 by the authors; licensee Cogitatio (Lisbon, Portugal). This article is licensed under a Creative Commons Attribution 4.0 International License (CC BY).

\section{Introduction}

Students who are hard of hearing $(\mathrm{HOH})^{1}$ are increasingly being granted access to university in both developed and developing countries, yet they remain signifi- cantly under-represented and under-supported in higher education, often resulting in poor academic outcomes with high levels of attrition (low persistence) (Rawlings, Karchmer, DeCaro, \& Allen, 1991; Stinson \& Walter, 1997). This situation places a growing obligation on uni-

\footnotetext{
${ }^{1}$ Terminology in deaf education is often derived from two paradigms. Firstly, the socio-cultural-linguistic view which associates deaf people with sign language and a culture. The second paradigm is characterised by the medical-audiology perspective, which encompasses ear and hearing health, diagnostics, rehabilitation and auditory assistive technology (Lomas, Andrews, \& Shaw, 2011). These two paradigms often influence the identity of learners with hearing loss. In this article, which falls within the latter paradigm, the term has been used to refer to people who present with varying degrees of hearing loss and who choose to make use of spoken language in conjunction with auditory assistive technology.
} 
versities to improve the overall teaching and learning support provided for these students in order to have a positive influence on their overall academic experience and eventual economic independence. This is of relevance in South Africa, where Higher Education Institutions (HEls) are accepting and registering students with a mild, moderate, severe or profound hearing loss, but are failing to provide the necessary academic support, and accessible and inclusive curricula (Department of Higher Education and Training [DHET], 2018; Foundation of Tertiary Institutes of the Northern Metropolis [FOTIM], 2011).

Hearing loss is the fourth highest cause of disability globally. Disabling hearing loss can be defined as a loss greater than $40 \mathrm{~dB}$ in adults and $30 \mathrm{~dB}$ in children (World Health Organization [WHO], 2018). According to the WHO, it is estimated that there are currently 466 million people with a 'disabling' hearing loss globally, projected to be 630 million by 2030. Globally, hearing loss is also the most common congenital anomaly found in newborns, occurring in approximately two to four infants per 1000 (Delaney, 2015). Of the 466 million people worldwide who have some form of hearing loss, two thirds live in low- and middle-income countries (WHO, 2018). In South Africa people with disabilities make up $7.5 \%$ of the total population (Statistics South Africa, 2011). The data reveal that $0.1 \%$ of the population 'cannot hear at all', $0.5 \%$ experiences 'a lot of difficulty', $2.9 \%$ experiences 'some difficulty' and the balance, $96.4 \%$, has 'no difficulty' in hearing. These figures show clearly that people with hearing loss make up the largest, single disability grouping in the country. Approximately 16 to 17 babies are born every day in South Africa with a hearing loss and many of them remain undiagnosed and untreated (Swanepoel, Storbeck, \& Friedland, 2009).

The 2015-2016 figures for the global prevalence rate of students with disabilities from the Higher Education Statistical Agency (HESA, 2017) showed that, in the United Kingdom, $11.7 \%$ of registered students, at all levels of study, have some form of disability. Of this overall figure, 2.33\% disclosed being Deaf or HOH (HESA, 2017). In Australia, the number of students with disabilities has also increased annually (Brett, 2010) with an overall participation rate of $4.3 \%$ in 2013 , with students with a hearing loss comprising approximately $10 \%$ of disability disclosures (DET, 2013). From the available data, it is thus evident that, despite increasing participation rates, students with disabilities, including students who are Deaf or $\mathrm{HOH}$, are still under-represented in higher education, not only in developing countries such as South Africa, but also in the developed world. This is a matter for concern since participation in higher education should result in access to better-paid occupations and professions (Branine, 2015; Ndlovu \& Walton, 2016). Furthermore, according to Richardson (2001), the low numbers of students with hearing loss (Deaf and $\mathrm{HOH}$ ) in higher education affects both the individual as there is a personal cost and, indirectly, the economy.
Globally, literature concerning how Deaf and $\mathrm{HOH}$ students experience higher education is limited (Schroedel, Watson, \& Ashmore, 2003), with much of the existing research focusing on children and not considering the implication for their capabilities as adults (Richardson, MacLeod-Gallinger, McKee, \& Long, 2000). A body of knowledge about the characteristics of obstacles faced exists but much less is known about potential solutions to the problem or the effectiveness of support services such as note-taking and real-time captioning for Deaf students (Lang, 2002; Stinson, Elliot, \& Kelly, 2017). However, what is known is that, many of those students who do enter higher education, do not graduate successfully and many of those who do graduate, continue to be excluded from professions, especially when the high demands of theory and practice in preparation for specific professions pose particular challenges (Ndlovu \& Walton, 2016). According to Rawlings, Karchmer, DeCaro and Allen (1991), up to $75 \%$ of Deaf and $\mathrm{HOH}$ students do not graduate from post-secondary educational institutions.

These global trends are also relevant in South Africa where HEls are accepting and registering students with mild, moderate, severe or profound hearing loss, but are failing to provide the necessary academic support, and accessible and inclusive curricula (Department of Education-South Africa [DOE-SA], 1997, 1998; DHET, 2018; FOTIM, 2011). Generally, there is a lack of research on Deaf students in tertiary institutions in South Africa (Moloi \& Motaung, 2014). Similarly, research concerning students who are $\mathrm{HOH}$ and who make use of spoken language is extremely limited so very little is known about their educational experiences and/or the teaching and learning support provided to them.

In South Africa, almost no research has been conducted regarding the teaching and learning needs of $\mathrm{HOH}$ students who are in higher education or the coping strategies they employ in order to survive academically (FOTIM, 2011). The studies that have been undertaken are mostly focused on training teachers of the Deaf, early hearing detection and intervention, development of Deaf identity, Sign Language and Deaf adults' views on Deaf Education in South Africa (Storbeck, 1998).

After two decades of democracy, university enrolments in South Africa have increased radically, but racial and other discrepancies remain (DHET, 2013, 2018). The South African Bill of Human Rights is the cornerstone in the Constitution of the Republic of South Africa of 1996 (Republic of South Africa [RSA], 1996, act 108). The Constitution states clearly that: "Everyone is equal before the law and has the right to equal protection and benefit of the law. Equality includes the full and equal enjoyment of all rights and freedoms" (RSA, 1996, article 9). The Constitution protects and supports the principles of human rights that inform all legislation, regulations and policies developed since 1996. Therefore, higher education policies spell out clearly the need to redress historical inequalities, transform the higher education system 
to serve a new social order better, improve the quality of life for all citizens and free their potential, respond to new realities and opportunities as well as increase university participation rates through the 'massification' of higher education (DHET, 2013; DOE-SA, 2001a; RSA, 1996). Access is almost universal today, but there is still a need to create equity, i.e., where people with disabilities can participate fully, feel that they fully belong and are set up for success.

Clearer norms and standards for the inclusion and success of students and staff with disabilities in the postschool sector were only given recently in the form of the White Paper on Post-School Education and Training (DHET, 2013) and, more specifically, the Strategic Policy Framework on Disability for the Post-School Education and Training System (DHET, 2018). The DHET's approach to disability and education was informed by landmark, international treaties and protocols ratified by South Africa, including the Universal Declaration of Human Rights (United Nations [UN], 1948), the United Nations Convention on the Rights of Persons with Disabilities and Optional Protocol to the Convention (UN, 2006), the United Nations 2030 Agenda for Sustainable Development (UN, 2015), and the Protocol to the African Charter on Human and Peoples' Rights on the Rights of Persons with Disabilities in Africa (African Commission on Human and People's Rights, 2016). Furthermore, relevant South African legislation, policy and regulations were developed for education and disability, including the White Paper on Integrated National Disability Strategy (INDS) (Office of the Deputy President, 1997), the reworked INDS now called the White Paper on the Rights of People with Disabilities (Department of Social Development, 2015), the National Plan for Higher Education (DOE-SA, 2001b), and the Education White Paper 6 on Special Education: Building an Inclusive Education and Training System (DOE-SA, 2001a).

With regards to teaching and learning, the Strategic Policy Framework on Disability for the Post-School Education and Training System states that:

Teaching and learning practices as well as the pedagogical design of curricula should reflect the context of social inclusion in institutions. This Strategic Policy Framework on Disability calls for critical engagement and improvement of current teaching and learning practices as well as pedagogical design of curricula in the context of inclusion of people with disabilities. (DHET, 2018, p. 57)

The infrastructure and support for teaching and learning should be based on universal design principles. In the higher education environment in South Africa, statistics regarding the numbers of university students who have disclosed disabilities, and more specifically hearing loss, are not readily available owing to factors such as differing definitions of disability, misinterpretation of disability codes on university application forms and stigma as- sociated with disclosure of a disability (Bell, 2013). Students often elect not to disclose their disability status, as their self-identity is that of a 'non-disabled' person and they see no social benefit to be gained from being identified as disabled (Mutanga, 2013). However, a study conducted by the FOTIM (2011), involving 15 South African universities, reported the following statistics concerning students with disabilities:

- The proportion of students with disabilities as a percentage of the total student population was less than $1 \%$;

- Disability units support between 21 and 400 students per year on average; and

- Very few disability units provide support services for students who are $\mathrm{HOH}$ and even less so for Deaf students who make use of Sign Language.

In 2012, the National Student Financial Aid Scheme (NSFAS), which funds needy but capable students in higher learning, allocated R45.5 million in bursaries to 1,368 students with disabilities. This was increased to R69.9 million in 2014, benefiting 1,383 students as from 12 February 2015. Ndlovu and Walton (2016) purport that this funding might not be adequate for studying professional degrees in higher learning with limited extended support being provided to students with disabilities during their fieldwork. Furthermore, according to the Higher Education Management Information System (HEMIS) data, the number of enrolled students with disabilities increased from 5,856 in 2011 to 7,110 in 2013 and, over the period of 2010 to 2015, the increase was from 5,357 to 7,379 (DHET, 2018). It is thus clear that the number of students with disabilities accessing higher learning is increasing every year. HEMIS (2010) data obtained from the DHET for the period between 2003 and 2010 indicated that the number of students with hearing impairment registered at HEls in South Africa increased from only 155 in 2003 to 326 in 2010 . Without current statistics being available in South Africa, it can be assumed from the aforementioned figures that the increase in the overall number of students with disabilities attending university would include students who might be Deaf or $\mathrm{HOH}$.

The aims of this article were to report on the teaching and learning experiences of $\mathrm{HOH}$ students who prefer to make use of spoken language to share the daily barriers with which they are faced, and to provide recommendations for teaching and learning, as well as curricula transformation.

The following sections are focused on a review of the literature and the empirical study. The background theory emphasizes: 1) the conceptualisation of inclusive education in South Africa and its effectiveness; 2 ) inclusion within higher education; 3 ) the potential effect of hearing loss on learning; and 4) types of support services for $\mathrm{HOH}$ students; and the barriers experienced by these students. 


\section{Review of the Literature}

\subsection{Conceptualising Inclusive Education}

Inclusive education is generally viewed as an 'overall principle that should guide all educational policies and practices; building on the premise that education is a basic human right and the foundation for a more equal and just society' (UNESCO, 2009, p. 8). Being 'inclusive', as argued by Thomas and O'Hanlon (2004, p. xi), involves more than simple integration or mainstreaming as it is deeply entrenched in a wide range of social, political, psychological and educational contexts. The philosophy of inclusion is concerned with creating and developing a system in which both equity and diversity are the goals and are truly welcomed. However, inclusion can be interpreted very differently depending on the specific context (Yssel, Engelbrecht, Oswald, Eloff, \& Swart, 2007).

In the South African educational system, inclusive education is defined primarily as a learning environment that promotes full personal, academic and professional development of all learners irrespective of race, class, gender, disability, religion, culture, sexual preference, learning style or language' (DOE-SA, 2001a, p. 16). The decision by the government to follow international trends regarding inclusion, i.e., to embark on a process to provide a more just, unified and equitable system for all, was a critical step for education in South Africa. However, inclusion cannot be achieved without the provision of relevant and adequate resources and support to ensure effective implementation across all levels of education (Swart \& Pettipher, 2018). As argued by Howell and Lazarus (2003), change to accommodate students with disabilities needs to take place at a discursive level, as well as at the level of institutional organisation and practice.

Various researchers have investigated the influence and effectiveness of inclusive practices on students' educational experiences. In their review of the literature on inclusion, Salend and Duhaney (1999) concluded that the benefits of inclusion for students with disabilities might include gains in academic achievement, increased peer acceptance and richer friendship networks, higher selfesteem, avoidance of stigma, and possible lifetime benefits such as higher salaries and independent living. Inclusive education has the potential to bring about equalisation of opportunity with regards to education and social life, particularly in countries where it has been well organised (Abosi \& Koay, 2008, p. 2). However, in South Africa, this situation of equalisation of opportunity is yet to be realised fully with the United Nations Convention on the Rights of Persons with Disabilities (UN, 2006) not having been properly domesticated yet (Human Rights Watch, 2015). Evidence clearly suggests that, although policy frameworks promote inclusive education within the ambit of 'education for all', a different reality of 'exclusive' education is revealed in practice (Armstrong, 2003; Booth, 2000). A recent monitoring report of the Convention on the Rights of the Child acknowledged that 'the challenges faced by children with disabilities in realizing their right to education remain profound' and that they are 'one of the most marginalized and excluded groups in respect of education' (UNICEF, 2013). The Human Rights Watch (2015) also revealed South Africa's dismal failure to provide inclusive education for children with disabilities.

\subsection{Inclusion within Higher Education}

Inclusive education is both a global imperative (UN, 2006) and a national priority in South Africa, which has a strong legislative framework (DHET, 2013; DOE-SA, 2001a) that provides guiding principles and parameters for implementation. Despite this progressive legislative and policy framework, students with disabilities, especially in higher education, continue to face a multitude of barriers-physical, social and attitudinal (FOTIM, 2011; Ndlovu \& Walton, 2016). Presenters at the 2009 African Network on Evidence-to-Action in Disability (AfriNEAD, 2009) conference highlighted infrastructural, institutional and environmental barriers faced by students with disabilities in higher education, including 'inaccessible environments, lack of reasonable accommodation, negative attitudes, discriminatory application and admission procedures and lack of disability policies and resources that unnecessarily disadvantage disabled students' (Lyner-Cleophas, Swart, \& Bell, 2009). Although there has been a considerable increase in graduates with disabilities in the system (984 graduates in 2011 to 1,294 in 2013), the attrition rate is still significantly high (SA News, 2015). Furthermore, evidence clearly shows that very few people with disabilities acquire professional degrees and, even those that do, are often excluded from professional jobs (Ndlovu \& Walton, 2016).

In essence, it is clear that, despite the progressive legislative framework in South Africa and the noble commitment to right the wrongs of the past, students with disabilities in higher education still remain marginalised and insufficiently supported. Those who are fortunate enough to gain access to higher education still face many barriers which not only impinge on their human rights but also affect the quality of their experience of education, which has a direct effect on their educational outcomes.

\subsection{Potential Effect of Hearing Loss on Learning}

The effect of the loss of functional hearing depends primarily on the type, extent and timing of the hearing loss. According to Tucci, Merson and Wilson (2009), mild to moderate hearing loss in children might lead to delays in the development of spoken language, whilst profound hearing loss could lead to significant delays in speech and language development. These delays often result in individuals with a hearing loss who prefer spoken language, being unable to acquire adequate oral communication skills. Without audiological and speech interventions, 
$\mathrm{HOH}$ children might never develop speech and language or any ability to communicate effectively. Moreover, a significant hearing loss might inhibit the social interaction of students and, if they communicate using speech, articulation problems sometimes make it difficult to understand them (Lewis \& Doorlag, 1999). Some $\mathrm{HOH}$ students in higher education might exhibit some or all of the following traits (Sheffield Hallam University [SHU], n.d.):

- Difficulty producing discussion elements of an assignment, particularly where these depend on abstract thinking rather than practical observation;

- Taking longer to read, understand and absorb information;

- Relying heavily on dictionaries, references and tutors to check their understanding; and

- Often having low self-confidence regarding their academic work.

The fact that these consequences of the hearing loss are completely independent of the intellectual ability or potential of a student who is $\mathrm{HOH}$ has been highlighted by Burke (2010). Luckner and Bowen (2006) assert that even though students with hearing disabilities are able to master the academic content, their ability to demonstrate academic performance is compromised because of delays in developing communication, language, reading and writing skills.

\subsection{Types of (Internal) Support Services for $\mathrm{HOH}$ Students in Higher Education}

At university level, the responsibility to request support services lies with the student (Boutin, 2008; Gardner, Barr, \& Lachs, 2001). However, when a student with an identified disability is admitted, it is the university's responsibility to provide reasonable accommodations that will provide equity of access to the physical as well as the teaching and learning environment. Support services available to $\mathrm{HOH}$ students vary greatly between universities in terms of quality of delivery and availability. Cawthon, Nichols and Collier (2009) maintain that the services that address the communication needs of $\mathrm{HOH}$ students might be an important predictor of these students' success at enrolling for, and completing, a degree. The types of support services available to $\mathrm{HOH}$ students could include: manual note-taking by human note-takers, academic tutors, instructional and curricula adaptations, language modification (e.g., of assessments to simplify the language), extra time, induction loop systems, realtime captioning and assistive devices, for example, personal FM-systems and vibrating alert devices.

\subsection{Barriers Experienced by $\mathrm{HOH}$ Students in Higher Education}

Students with varying degrees of hearing loss face a multitude of barriers in higher education. In the researchers' opinion, there could be many reasons why these barriers exist, such as: lack of support; lack of awareness of the accommodation needs of these students; the 'invisibility' and uniqueness of their hearing loss and thus complex support needs; teaching staff ignoring calls to attend disability-related, professional development courses; attitudinal barriers of faculty members; and lack of financial and human resources. This array of factors could make it unattractive to universities to admit students who are $\mathrm{HOH}$, resulting in under-representation in higher education. The subsequent barriers, as reported by Howell (2006), have a profound and sustained effect on the psycho-social well-being and functioning of the students. In general, students with disabilities, who have managed to attend HEls, argue that the energy, emotional resources and levels of stress involved in dealing with the wide range of barriers they are confronted with undermine them and place them at an ongoing disadvantage in relation to other students. If they are unable to deal with these issues, the prevailing attitudes and prejudices towards their abilities are reinforced. Reindal (1995) argues that students with sensory disabilities encounter so many practical difficulties that their ability to study can be undermined, which often results in attrition or lack of persistence in higher education.

\subsection{Attrition, Persistence and Academic Outcomes}

As previously mentioned, the participation figures of students with a hearing loss in higher education are very low and, of those students who do enter higher education, many do not graduate successfully owing to a variety of factors such as lack of support. The gap in academic achievement between students who hear and those with a hearing loss is often reported (Marschark, 2006; Moores, 2003).

Attrition refers to the gradual decline in the number of registered students (Tinto, 1987). The highest rate of attrition commonly occurs during the first year of study at university. The same truth applies to students who are $\mathrm{HOH}$. According to Allen (1986), almost $75 \%$ of students with hearing loss do not graduate from post-secondary educational institutions (including colleges and universities). In a later study, Stinson and Walter (1997) also found that the two- and four-year college retention rates for students with hearing loss were considerably lower than those for students who can hear.

Tinto (1987) explains that persistence means to remain in college until graduating whether multiple institutions of higher education are attended or not and, in a later study, he found that persistence is particularly important during the first year of college since most attrition occurs at this time (Tinto, 1998). In post-secondary institutions in the United States, according to a study by Albertini, Kelly and Matchett (2012), only approximately $35 \%$ of deaf (Deaf and $\mathrm{HOH}$ ) students graduate from twoyear programmes, compared with approximately $40 \%$ of their hearing peers; and according to Marschark, Lang 
and Albertini (2002), approximately $30 \%$ of Deaf students graduate from four-year programmes compared with approximately $70 \%$ of their hearing peers.

Tinto (1987) argues that it is important to monitor the progress of deaf and $\mathrm{HOH}$ students, particularly during the most vulnerable first 10 weeks of study since, generally, attrition is highest during this period (Boutin, 2008). A central aspect of Boutin's persistence model is that students need to be integrated into both the academic as well as the social systems of the university (Boutin, 2008). Research conducted with degree-level students showed that Deaf students do not feel as much a part of the 'university family' as their hearing peers, which could influence their educational success (Foster, Long, \& Snell, 1999).

In the next section, the context of this case study and participants' details are provided and the method used is described.

\section{Method, Participants and Context}

A qualitative approach was used, and interviews were conducted with students who were $\mathrm{HOH}$ and were attending the university in South Africa at which this case study was carried out. The case study was descriptive in nature, adopting a constructivist paradigm to explore and describe the lived and subjective learning experiences shared by the students studying at a 'hearing' university. Using both the participants' and the researchers' understanding, the participants' social worlds were explored (Ritchie \& Lewis, 2003). The main research goal of this study was to explore and describe the academic teaching and learning experiences of students with hearing impairments, using the oral method of communication, at the university participating in the study.

The university involved was chosen because, at the time of the study, it had the highest enrolment of students who were $\mathrm{HOH}$ and thus it was presumed to have accrued experience in supporting these students. Only students with a hearing loss who preferred to use spoken language were selected for this study as they were given access to HEls in South Africa more readily than Deaf students at the time. More recently Deaf students have been admitted and provided with Sign Language interpreters.

\subsection{The Case Study Institution}

This research was undertaken at one of the public universities in South Africa. The student body in 2014 comprised approximately 29,000 students with an equal distribution of male and female students. The university had a disability unit, a policy for students with disabilities, which subscribed to the social model of disability (Oliver, 2004) and defined the term 'disability' as referring to 'a verifiable physical, non-visible and/or psychological limitation/s which negatively affects [a student's] daily activities in a specific way. ${ }^{2}$ Although the study corps was rela-

\footnotetext{
${ }^{2}$ No reference is provided to protect the anonymity of the institution.
}

tively diverse in terms of ethnicity, culture and language, only $1.7 \%$ of the total student population disclosed having a disability on their application forms.

\subsection{Selecting and Describing the Participants}

Typical of case study methodology, a purposeful sampling procedure was used (Silverman, 2010). The criteria for inclusion of students in the study were that they:

- Had to have a hearing loss, regardless of type, degree or age of onset;

- Needed to be registered students at the case study university; and

- Had to make use of spoken language as their primary mode of communication, i.e., not Sign Language.

Students who had disclosed their hearing loss to the disability unit were invited by email to participate in the study. Seven out of a possible thirteen students responded positively as shown in Table 1.

\subsection{Data Generation Methods}

Qualitative data were generated by conducting individual, in-depth interviews, lasting approximately 1.5 hours each, having received prior consent. Preceding each interview, the participants were requested to complete a biographical questionnaire which provided background data (see Table 1). All the interviews were held in a quiet environment to facilitate barrier-free communication, were conducted in English and were digitally recorded. A printed copy of the interview guide was provided to the participants, so they could read the questions as well as listen to them being posed.

\subsection{Data Analysis and Ethical Considerations}

ATLAS.ti (version 6) was used to code the transcribed interviews, to develop categories and themes and to build various network views (Charmaz, 2006). The grounded theory coding process involving the initial phase, focused/selective phase and the theoretical coding phase, as explained by Charmaz (2006), was used. The measures used to ensure trustworthiness of the data were crystallisation (Richardson, 2000), member checks (Holloway, 1997), peer review (Merriam \& Tisdell, 2016) and an audit trail (Silverman, 2010). The following ethical arrangements were taken into consideration in this study: informed consent, anonymity and confidentiality, and protecting the participants from any harm.

\section{Findings and Discussion}

The results have been presented in terms of four key themes: 
Table 1. Biographical data for each student participant.

\begin{tabular}{|c|c|c|c|c|c|c|c|c|}
\hline $\begin{array}{l}\text { Participant } \\
\text { Pseudonyms }\end{array}$ & Age & Gender & $\begin{array}{l}\text { Year of } \\
\text { study }\end{array}$ & Onset & $\begin{array}{l}\text { Degree of hearing } \\
\text { impairment }\end{array}$ & $\begin{array}{l}\text { Audiological } \\
\text { devices }\end{array}$ & $\begin{array}{l}\text { First } \\
\text { language }\end{array}$ & Ethnicity \\
\hline Barry & 23 & Male & $3^{r d}$ & $\begin{array}{l}\text { Birth } \\
(L \& R)\end{array}$ & $\begin{array}{l}\text { Profound } \\
\text { implant (R) }\end{array}$ & Cochlear & English & White \\
\hline Merle & 21 & Female & $3^{r d}$ & Birth & $\begin{array}{l}\text { Moderate } \\
(L \& R)\end{array}$ & None & Afrikaans & White \\
\hline Paul & 24 & Male & $3^{\text {rd }}$ & Birth & Profound (R) & $\begin{array}{l}\text { BTE* hearing } \\
\text { aid }(R)\end{array}$ & Afrikaans & White \\
\hline Astrid & $\begin{array}{l}24 \\
6\end{array}$ & Female & $\begin{array}{l}4^{\text {th }} \\
R=8 \mathrm{yr}\end{array}$ & $\begin{array}{l}\mathrm{L}=4 \mathrm{yr} \\
(\mathrm{L} \& \mathrm{R})\end{array}$ & $\begin{array}{l}\text { Profound } \\
\text { implant (R) }\end{array}$ & Cochlear & English & White \\
\hline Colin & 20 & Male & $1^{\text {st }}$ & Birth & $\begin{array}{l}\text { Moderate } \\
(L \& R)\end{array}$ & $\begin{array}{l}\text { BTE hearing } \\
\text { aid }(R)\end{array}$ & Afrikaans & White \\
\hline Stewart & 20 & Male & $1^{\text {st }}$ & Birth & $\begin{array}{l}\text { Severe } \\
(L \& R)\end{array}$ & $\begin{array}{l}\text { BA*** hearing } \\
\text { aid }(L \& R)\end{array}$ & Afrikaans & White \\
\hline Noelene & 19 & Female & $1^{\text {st }}$ & $\begin{array}{l}\mathrm{L}=2 \mathrm{yr} \\
\mathrm{R}=10 \mathrm{yr}\end{array}$ & $\begin{array}{l}\text { Profound } \\
\text { (L \& R) }\end{array}$ & $\begin{array}{l}\text { Cochlear } \\
\text { implant (R) }\end{array}$ & English & White \\
\hline
\end{tabular}

Notes: ${ }^{*} \mathrm{~L}=$ left and $\mathrm{R}=$ right; ${ }^{* *}$ Behind-the-ear; ${ }^{* * *}$ Bone-anchored

\subsection{Inclusive Teaching Practices and Curriculum Accessibility}

Teaching practices at the university were not inclusive and those practices that students with a hearing loss found useful, such as the provision of electronic notes and the use of electronic calendars were not deliberate attempts to be inclusive but were typical for postmodern universities in a technological age. The use of microphones was also not specifically intended to accommodate students who were $\mathrm{HOH}$ but was rather an attempt to enhance audibility for large classes. One useful practice was the provision of preferential seating in large classrooms. Unfortunately, without enforcement by the lecturer, these rows of seats would be occupied quickly and be unavailable to those who needed to be seated in the front to be able to hear and lip-read. One student shared her negative experiences in this regard:

There is space, like the first row, for students who have disabilities, but many times other students go sit there as well..... Lecturers should also say to the other students that they shouldn't sit there as this is reserved for the students with disabilities. (Merle)

It was also found that curricula were largely inflexible with little transformation having taken place at the university in order to accommodate $\mathrm{HOH}$ students. Existing curricula did not adhere to the principles of accessibility, flexibility or universal learning design and thus were not responsive to the needs of the students. Two students shared their experiences:

Well, the real barrier is communication and to overcome it I usually use my fellow students....They really
help....When a lecturer is explaining something it is frustrating because you can't always hear so I really do rely on the PowerPoint notes that they have on WebCT [online learning management system] as it explains the stuff to you. It is just frustrating because it is not like you can ask for the PowerPoint notes. If I could have heard what he said, maybe I could have seen that I don't understand and ask him, but I don't know what to ask because I can't hear what he is saying. (Colin)

Yes, some of the lecturer's notes are hard to find because they are not all on WebCT. They have their own website somewhere else, so you have to google search for it....[It's] very frustrating and I can't hear the lecturer, so that is also frustrating. (Noelene)

It was noted that similar findings regarding inaccessible teaching practices and curricula have been reported since 1998 at universities in South Africa yet the practices continue to prevail (Council on Higher Education [CHE], 2005; DHET, 2018; DOE-SA, 2005; FOTIM, 2011; Howell, 2006, p. 168). Based on their research, Cummings, Dyson and Millward (2003) reported that the focus of inclusive education was on organisational characteristics instead of important issues such as pedagogy, curriculum and educational outcomes. The findings from the present study were similar, indicating a need for real change. In research by McLean, Heagney and Gardner (2003), it was found that the lack of curriculum flexibility and the barriers to curriculum access developed because of the ways in which learning support services for students with disabilities had been conceptualised. Similarly, at the case study university, the conceptualisation of support was still based on the deficit model of disability (Oliver, 1989), which had an effect on student learning. 


\subsection{Reasonable Academic Adjustments}

Reasonable academic adjustments refer to strategies that minimise or eliminate the effect of a disability, enabling the individual to gain access to, and have equal opportunity to participate in, the university's courses, programmes, assessments, services and activities (Brinckerhoff, Shaw, \& McGuire, 1992; UN, 2006). Limited, reasonable academic adjustments had been made for students who were $\mathrm{HOH}$ at the university. However, only one of the participants had requested and received permission to make use of additional time for assessments: 'For the tests/exam I have extra time. I get 10 minutes per hour' (Paul). Generally, the participants were unaware of any academic adjustments (reasonable accommodations) available to them and either they felt that it was not necessary or that it would be an unfair advantage for them or they did not want to be subjected to the application procedure and be required to declare their disability. Colin shared his lack of awareness by stating: 'Not at all; I never even knew there was a support system for the students'.

\subsection{Learning Support}

At the time of this research, support services offered by the case study university to students who were $\mathrm{HOH}$ were largely inadequate. This included both human and technical support. Participants were mostly unaware of the availability of support services and thus the uptake of learning support was low. The only available learning support included academic tutoring, mentoring, extra time for assessments and the use of peers for taking notes or sharing their notes with the $\mathrm{HOH}$ students. In a recent study by Stinson et al. (2017) it was found that students rated the printed or electronic file text (part of the speech-to-text service), which they used for study after class, as being more useful than notes from a note taker. It was also important to note that both tutoring and mentoring were available to all university students.

One participant who made use of the note-taking service did not find it helpful as he struggled to interpret the notes taken, as they reflected someone else's filtering of the information based on their prior knowledge and context. Another student shared his feelings of discomfort having to rely on someone else for support in class:

In the Maths class the note taker will take the notes and I will just sit and try to listen to what the professor is saying.... feel a bit uncomfortable to rely on somebody else, because you want to do everything by yourself. (Barry)

There was a need for increased learning support at the case study university, such as academic one-to-one tutoring, as the teaching venues made learning inaccessible to students who were $\mathrm{HOH}$ owing to the unavailability of audio induction loop systems and other, well- functioning audio equipment such as public address (PA) systems using high-quality speakers or microphones. The learning support that was most urgently required, especially for students with a profound hearing loss, was realtime speech-to-text captioning.

\subsection{Barriers to Learning}

All of the participants experienced a significant number of barriers related to learning. These barriers were associated mostly with communication, teaching practices and assessment. The students' experiences varied, depending on the severity and age of onset of their hearing loss. The major barriers faced by $\mathrm{HOH}$ students related specifically to the audibility and accessibility of their primary (oral) mode of communication. Examples of typical barriers shared by the participants were:

- Inability to hear or lip-read the lecturer, especially when switching between two languages without warning;

- Difficulty following class discussions, high levels of background noise and poor acoustics, especially in large venues;

- Inaccessible teaching practices, such as the lecturer talking whilst writing on the board, and videos without subtitles;

- Poor lighting when using a data/video projector as $\mathrm{HOH}$ students were not able to lip-read; and

- Lecturers not making use of audio equipment or the equipment being in a state of disrepair or not available at all.

Three students share their 'lived' experiences:

[Following class discussions] If a student is sitting in front of me then it can be quite a problem because the sound is away from you and you are not able to lip-read...that is a problem. I can't always follow because some lecturers don't repeat the question, they just answer, and I don't know what was asked. (Paul)

But sometimes I will ask them to speak, like, many lecturers don't like to use the microphone, but the class will ask them to use it, and they will be like, 'I will just do this [speak louder without the microphone]', but it doesn't really help, like, them standing in front or trying to talk louder...it doesn't help. It is very frustrating. (Merle)

Another participant expressed experiencing severe frustration when he could not hear during class because of a lecturer speaking indistinctly. This created a communication barrier, not only for him, but even for all the 'hearing' students in the class: 'The frustrating thing is that the lecturer doesn't really speak very clearly. My friends with normal hearing even struggle to hear the lecturer' (Colin). 
It seemed that the common thread throughout this discussion was that students who were $\mathrm{HOH}$ were not aware of available learning support, albeit insufficient, which precluded them from accessing it. This, in turn, resulted in these students experiencing many barriers and having to devise their own personal coping strategies. At the time of the study, $\mathrm{HOH}$ students at the case study university faced many barriers. These barriers, including attitudinal, pedagogical, communication, assessment practices and environmental barriers have the potential to affect the students' educational experience and their academic attainment negatively.

\section{Conclusion and Recommendations}

The purpose of this study was to explore the learning experiences of $\mathrm{HOH}$ students at a South African university. Various exclusionary practices were identified, which resulted in these students facing significant barriers to learning. The barriers they shared were based on their lived experience. While some attempts had been made by the case study university to be more inclusive, these students were inadequately supported in terms of their unique learning and communication needs.

The participants made a number of recommendations regarding curriculum flexibility and transformation in order to reduce the learning barriers experienced:

- Lecturers should:

- Learn and apply the principles of universal learning design in their curriculum design, chosen materials and delivery methods;

- Attend staff development workshops to increase their knowledge and raise their awareness of how to provide adequate support for students who are $\mathrm{HOH}$ in their classes;

- Ensure that they are aware of the needs of each individual student and his/her specific needs by collaborating with the disability support services;

- Make glossaries of new and complex terminology available prior to it being taught in class and provide electronic copies of detailed notes well in advance to allow for prereading of materials;

- Be available to meet with the students oneto-one, and their primary mode of general, 'out-of-class' communication should be by email;

- Insist that the first one or two rows in a large venue be kept open for students with special communication needs, e.g., students who are $\mathrm{HOH}$, and make use of specialised audio equipment;

- Repeat questions asked and answered in class by other students and ensure that all audio-visual materials have subtitles.
- Interaction amongst Deaf or $\mathrm{HOH}$ peers should be encouraged as this might help with some of the issues raised, e.g., sharing of knowledge/notes, etc.;

- Support and access must be made available to all $\mathrm{HOH}$ or Deaf university students regardless of their communication preference;

- Any support provided should be tailored to address individualised needs;

- Large teaching venues should be fitted with goodquality, audio equipment which is well maintained;

- Additionally, as suggested by Chataika, McKenzie, Swart and Lyner-Cleophas (2012), a compulsory module on diversity, disability and inclusion should be implemented for every university student, and lecturers should be included, to produce future leaders and policy makers who are sensitive to disabilities.

While acknowledging that the university involved in the case study provided some support, it has been argued that this was insufficient to meet the real and unique needs of each student with hearing loss who preferred to use spoken language to communicate. It is therefore the researchers' contention that, unless strategies are put into place to support students who are $\mathrm{HOH}$ in higher education better, they will continue to experience significant barriers to learning that will have a potentially negative effect on their educational experience as well as their academic attainment. Upon accepting and registering students with disabilities, it is incumbent upon universities to provide adequate and appropriate support to ensure that these students have equitable access to learning and thus fair opportunity for educational success. A call to action is required for university administrators, lecturers and students to support and participate in awareness workshops.

This also implies that there is a need for cultural change towards understanding and support within universities for them to become truly inclusive for all.

\section{Acknowledgements}

The authors wish to thank the participants for sharing their experiences and insights during the course of this research.

\section{Conflict of Interests}

The authors declare no conflict of interests.

\section{References}

Abosi, O., \& Koay, T. L. (2008). Attaining development goals of children with disabilities: Implications for inclusive education. International Journal of Special Education, 23(3), 1-10.

African Commission on Human and People's Rights. (2016). Draft protocol to the African charter on hu- 
man and peoples' rights on the rights of persons with disabilities in Africa. Banjul: ACHPR. Retrieved from www.achpr.org/files/news/2016/04/d216/disability_ protocol.pdf

AfriNEAD. (2009). The ABC of research evidence-toaction: Putting UNCRPD principles into action for rights-based change (Conference Report for the AfriNEAD Symposium). Cape Town: The Centre for Rehabilitation Studies, Stellenbosch University.

Albertini, J. A., Kelly, R. R., \& Matchett, M. K. (2012). Personal factors that influence deaf college students. Journal of Deaf Studies and Deaf Education, 17(1), 85-101.

Allen, T. E. (1986). Patterns of academic achievement among hearing impaired students: 1974 and 1983. In A. Schildroth \& M. Karchmer (Eds.), Deaf children in America (pp. 161-206). Boston, MA: College-Hill Press.

Armstrong, D. (2003). Experiences of special education: Re-evaluating policy and practice through life stories. London: Routledge-Falmer.

Bell, D. (2013). Investigating teaching and learning support for students with hearing impairment at a university in the Western Cape (Unpublished Doctoral Dissertation). University of Stellenbosch. Retrieved from http://hdl.handle.net/10019.1/80004

Booth, T. (2000). Inclusion and exclusion policy in England: Who controls the agenda? In F. Armstrong, D. Armstrong, \& L. Barton (Eds.), Inclusive education: Policy, contexts and comparative perspectives (pp. 78-98). London: David Fulton.

Boutin, D. L. (2008). Persistence in postsecondary environments of students with hearing impairments. Journal of Rehabilitation, 74(1), 25-31.

Branine, M. (2015). A comparative analysis of graduate employment prospects in European labour markets: A study of graduate recruitment in four countries. Higher Education Quarterly, 69(4), 342-365.

Brett, M. (2010). Challenges in managing disability in higher education, illustrated by support strategies for deaf and hard of hearing students. The Open Rehabilitation Journal, 3, 4-8.

Brinckerhoff, L. C., Shaw, S. F., \& McGuire, J. M. (1992). Promoting access, accommodation, and independence for college students with learning disabilities. Journal of Learning Disabilities, 25(7), 417-429.

Burke, M. (2010). Disabled student support team. Sheffield: Sheffield Hallam University.

Cawthon, S. W., Nichols, S. K., \& Collier, M. (2009). Facilitating access: What information do Texas postsecondary institutions provide on accommodations and services for students who are deaf or hard of hearing? American Annals of the Deaf, 153(5), 450-460.

Charmaz, K. (2006). Constructing grounded theory: A practical guide through qualitative analysis. London: Sage.

Chataika, T., McKenzie, J. A., Swart, E., \& Lyner-Cleophas, M. (2012). Access to education in Africa: Respond- ing to the United Nations convention on the rights of persons with disabilities. Disability \& Society, 27(3), 385-398.

Council on Higher Education. (2005). Higher education monitor: South African higher education responses to students with disabilities. Pretoria: Council on Higher Education.

Cummings, C., Dyson, A., \& Millward, A. (2003). Participation and democracy: What's inclusion got to do with it? In J. Allan (Ed.), Inclusion, participation and democracy: What is the purpose? (pp. 49-66). Dordrecht: Kluwer Academic Publishers.

Delaney, A. (2015). Newborn hearing screening. Medscape. Retrieved from emedicine.medscape.com/ article/836646-overview

Department of Education-South Africa. (1997). Education White Paper 3: A programme for the transformation of higher education. Pretoria: Government Printer.

Department of Education-South Africa. (1998). Quality education for all. Overcoming barriers to learning and development (Report of the National Commission on Special Needs in Education and Training and the National Committee on Education Support Services). Pretoria: Government Printer.

Department of Education-South Africa. (2001a). Education White Paper 6 on special needs education: Building an inclusive education and training system. Pretoria: Department of Education.

Department of Education-South Africa. (2001b). National plan for higher education. Pretoria: Government Printer.

Department of Education-South Africa. (2005). CurricuIum adaptation guidelines of the revised national curriculum statement. Pretoria: Government Printer.

Department of Higher Education and Training. (2010). HEMIS statistics: Students who disclosed hearing impairment (2003-2010). Pretoria: Government Printer.

Department of Higher Education and Training. (2013). White Paper on post-school education and training. Pretoria: Government Printer.

Department of Education and Training. (2013). Table 2.1: Commencing and all domestic students by equity group, 2001 to 2013. Education.Gov. Retrieved from www.docs.education.gov.au/system/files/doc/other/ 2013appendix2_0.xls

Department of Higher Education and Training. (2018). Strategic policy framework on disability for the postschool education and training system. Pretoria: Government Printer.

Department of Social Development. (2015). White Paper on the rights of people with disabilities. Pretoria: Department of Social Development. Retrieved from www.gov.za/sites/www.gov.za/files/39792_gon230.pdf

Foster, S., Long, G., \& Snell, K. (1999). Inclusive instruction and learning for deaf students in postsecondary education. Journal of Deaf Studies and Deaf Educa- 
tion, 4(3), 225-235.

Foundation of Tertiary Institutes of the Northern Metropolis. (2011). Disability in higher education project report. Retrieved from www.uct.ac.za/usr/ disability/reports/annual_report_10_11.pdf

Gardner, D., Barr, V., \& Lachs, S. (2001). Students who are deaf or hard of hearing in postsecondary education. Washington, DC: Department of Education.

Higher Education Statistical Agency. (2017). First year UK domiciled HE students by level of study, gender, mode of study and disability status 2015/16. Hesa. Retrieved from www.hesa.ac.uk/ collection/c16051/a/disable

Holloway, I. (1997). Basic concepts for qualitative research. Oxford: Blackwell Science Ltd.

Howell, C. (2006). Disabled students and higher education in South Africa. In B. Watermeyer, L. Swartz, T. Lorenzo, M. Schneider, \& M. Priestley (Eds.), Disability and social change: A South African agenda (pp. 164-178). Cape Town: HSRC Press.

Howell, C., \& Lazarus, S. (2003). Access and participation for students with disabilities in South African higher education: Challenging accepted truths and recognising new possibilities. Perspectives in Education, 21(3), 59-74.

Human Rights Watch. (2015). "Complicit in Exclusion": South Africa's failure to guarantee an inclusive education for children with disabilities. New York, NY: Human Rights Watch.

Lang, H. G. (2002). Higher education for deaf students: Research priorities in the new millennium. Journal of Deaf Studies and Deaf Education, 7(4), 267-280.

Lewis, R. B., \& Doorlag, D. H. (1999). Teaching special students in general education classrooms (5th ed.). Upper Saddle River, NJ: Merrill, Prentice-Hall.

Lomas, G. I., Andrews, J. F., \& Shaw, P. C. (2011). Deaf and hard of hearing students from: Handbook of special education. Abingdon-on-Thames: Taylor \& Francis Ltd.

Luckner, J. L., \& Bowen, S. (2006). Assessment practices of professionals serving students who are deaf or hard of hearing: An initial investigation. American Annals of the Deaf, 151(4), 410-417.

Lyner-Cleophas, M., Swart, E., \& Bell, D. (2009). Transition from secondary to tertiary education: Stories of inclusivity. Paper presented at the AfriNEAD Symposium, Milnerton.

Marschark, M. (2006). Intellectual functioning of deaf adults and children: Answers and questions. European Journal of Cognitive Psychology, 18(1), 70-89.

Marschark, M., Lang, H. G., \& Albertini, J. (2002). Educating deaf students: From research to practice. New York, NY: Oxford University Press.

McLean, P., Heagney, M., \& Gardner, K. (2003). Going global: The implications for students with a disability. Higher Education Research \& Development, 22(2), 217-228.

Merriam, S. B., \& Tisdell, E. J. (2016). Qualitative re- search: A guide to design and implementation (4th ed.). San Francisco, CA: Jossey-Bass.

Moloi, K. C., \& Motaung, R. R. (2014). Admission of and service provision for deaf students at a university of technology. Mediterranean Journal of Social Sciences, 5(10), 370-375.

Moores, D. F. (2003). Short term memory, morphology, and reading. American Annals of the Deaf, 148(1), 3-4.

Mutanga, O. (2013). "I am a university student, not a disabled student": Conceptualising identity and social justice in South African higher education through the capabilities approach lens. Journal of Educational Studies, 12(1), 76-88.

Ndlovu, S., \& Walton, E. (2016). Preparation of students with disabilities to graduate into professions in the South African context of higher learning: Obstacles and opportunities. African Journal of Disability, 5(1). http://dx.doi. org/10.4102/ajod.v5i1.150

Office of the Deputy President. (1997). White Paper on an integrated national disability strategy (INDS). Pretoria: ODP.

Oliver, M. (1989). Disability and dependency: A creation of industrial societies? In L. Barton (Ed.), Disability and dependency (pp. 6-22). London: Falmer Press.

Oliver, M. (2004). The social model in action: If I had a hammer. In C. Barnes, C. Thomas, \& S. French (Eds.), Disabling barriers, enabling environments (pp. 7-12). London: Sage.

Rawlings, B. W., Karchmer, M. A., DeCaro, J. J., \& Allen, T. E. (1991). College and career programs for deaf students. Washington, DC: Gallaudet University Press.

Republic of South Africa. (1996). Constitution of the Republic of South Africa of 1996. Cape Town: Government Printers.

Reindal, S. M. (1995). Some problems encountered by disabled students at the University of Oslo: Whose responsibility? European Journal of Special Needs Education, 10(3), 227-241.

Richardson, J. T. E. (2001). The representation and attainment of students with a hearing loss in higher education. Studies in Higher Education, 26(2), 183-204.

Richardson, L. (2000). Writing: A method of inquiry. In N. K. Denzin \& Y. S. Lincoln (Eds.), The Sage handbook of qualitative research (pp. 923-948). Thousand Oaks, CA: Sage.

Richardson, J. T. E., MacLeod-Gallinger, J., McKee, B. G., \& Long, G. L. (2000). Approaches to studying in deaf and hearing students in higher education. Journal of Deaf Studies and Deaf Education, 5(2), 156-173.

Ritchie, J., \& Lewis, J. (2003). Qualitative research practice: A guide for social sciences students and researchers. London: Sage.

SA News. (2015). More students with disabilities in higher education. SA News. Retrieved from www. sanews.gov.za/south-africa/more-students-disabilities -higher-education

Salend, S. J., \& Duhaney, L. M. G. (1999). The impact of 
inclusion on students with and without disabilities and their educators. Remedial and Special Education, 20(2), 114-126.

Schroedel, J. G., Watson, D., \& Ashmore, D. H. (2003). A national research agenda for the postsecondary education of deaf and hard of hearing students: $A$ roadmap for the future. American Annals of the Deaf, 148(2), 67-73.

Sheffield Hallam University. (n.d.). Guidelines for working with deaf students in the teaching environment. Sheffield: Sheffield Hallam University.

Silverman, D. (2010). Doing qualitative research (3rd ed.). London: Sage.

Statistics South Africa. (2011). General household survey: 2010. Pretoria: Statistics South Africa.

Stinson, M. S., Elliot, L. B., \& Kelly, R. R. (2017). Deaf and hard-of-hearing high school and college students' perceptions of speech-to-text and interpreting/note taking services and motivation. Journal of Developmental and Physical Disabilities, 29(1), 131-152.

Stinson, M. S., \& Walter, G. (1997). Improving retention for deaf and hard of hearing students: What the research tells us. Journal of American Deafness and Rehabilitation Association, 30(4), 14-23.

Storbeck, C. (1998). A professional development programme for teachers of the deaf in South Africa (Unpublished Doctoral dissertation). Rand Afrikaans University, Johannesburg.

Swanepoel, D. W., Storbeck, C., \& Friedland, P. (2009). Early hearing detection and intervention in South Africa. International Journal of Pediatric Otorhinolaryngology, 73(6), 783-786.

Swart, E., \& Pettipher, O. R. (2018). Understanding and working with change. In P. Engelbrecht \& L. Green (Eds.), Responding to the challenges of inclusive education in Southern Africa (2nd ed., pp. 131-147). Pretoria: Van Schaik.

Thomas, G., \& O'Hanlon, C. (2004). Series editors' pref- ace. In G. Thomas \& M. Vaughan (Eds.), Inclusive education: Readings and reflections (pp. xi-xii). London: Open University Press.

Tinto, V. (1987). Leaving college: Rethinking the causes and cures of student attrition. Chicago, IL: University of Chicago Press.

Tinto, V. (1998). Colleges as communities: Taking research on student persistence seriously. The Review of Higher Education, 21(2), 167-177.

Tucci, D. L., Merson, M. H., \& Wilson, B. S. (2009). A summary of the literature on global hearing impairment: Current status and priorities for action. Otology \& Neurotology, 31(1), 31-41.

United Nations. (1948). Universal declaration of human rights. Paris. Retrieved from www.un.org/en/ universal-declaration-human-rights

United Nations. (2006). Convention on the rights of persons with disabilities. Paris. Retrieved from www.un. org/disabilities/documents/convention/convoptprote.pdf

United Nations. (2015). Transforming our world: The 2030 agenda for sustainable development. New York, NY: UN Publishing.

UNESCO. (2009). Policy guidelines on inclusion in education. Paris: UNESCO.

UNICEF. (2013). The state of the world's children. Children with disabilities. New York, NY: UNICEF. Retrieved from www.unicef.org/sowc2013

World Health Organization. (2018). Deafness and hearing loss. World Health Organization. Retrieved from www.who.int/en/news-room/fact-sheets/ detail/deafness-and-hearing-loss

Yssel, N., Engelbrecht, P., Oswald, M. M., Eloff, I., \& Swart, E. (2007). Views of inclusion: A comparative study of parents' perceptions in South Africa and the United States. Remedial and Special Education, 28(6), 356-365.

\section{About the Authors}
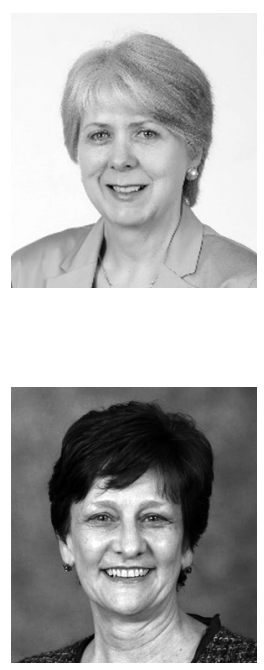

Diane Bell currently serves as the Director of the Carel du Toit Trust. In her previous positions she worked as a member of the Global Cooperation on Assistive Technology (GATE) team at the World Health Organization (WHO) in Geneva and served as the Academic Director at the University of Stellenbosch Business School Executive Development (USB-ED). She is a mother of a daughter born with a profound hearing impairment. Diane's doctoral thesis focused on students with hearing impairment in higher education and she has authored several journal articles and a book chapter on this topic. She also serves as a member of the Presidential Working Group on Disability in South Africa and currently consults for WHO in the area of assistive technology.

Estelle Swart is a Professor in the Department of Educational Psychology at Stellenbosch University, which she chaired for several years. She is a National Reseach Foundation rated researcher with an interest in disability in education, professional learning and support practices in inclusive education. Estelle is the co-editor of two books, Addressing Barriers to Learning (2016) and Understanding Educational Psychology (2018), and authored and co-authored chapters and articles in scholarly journals. She is a registered educational psychologist, was a member of the Health Professions Council of South Africa Board for Psychology and chaired of the Psychological Society of South Africa Division for Educational Psychology. 